\title{
ASPECTOS DA ESTRUTURA DA RAIZ E DO DESENVOLVIMENTO DE PLANTAS DE SOJA EM SOLOS COMPACTADOS ${ }^{1}$
}

\author{
RACHEL BENETTI QUEIROZ-VOLTAN², SANDRA DOS SANTOS SEVÁ NOGUEIRA ${ }^{3}$ \\ e MANOEL ALBINO COELHO DE MIRANDA ${ }^{3}$
}

\begin{abstract}
RESUMO - O objetivo deste trabalho foi avaliar o efeito da compactação do solo na anatomia da raiz e no desenvolvimento de duas cultivares de soja (Glycine max (L.) Merrill), IAC-8 e IAC-14, em vasos. O solo utilizado foi um Latossolo Roxo, tirado da camada superficial (0-200 mm). Os níveis de compactação consistiram de 0,95 (controle), 1,20,1,35 e 1,50 kg L $\mathrm{kg}^{-1}$, e foram obtidos pela compactação de determinada massa de solo por prensa hidráulica, em cilindros de ferro. A compactação do solo não afetou a estrutura anatômica da raiz, em nenhuma das duas cultivares. Na cultivar IAC-8, o número de folhas, a altura das plantas e o peso da matéria seca da raiz e do caule diminuíram com o aumento da densidade do solo, e o comprimento da raiz aumentou. Na cultivar IAC-14, o número de folhas, a área foliar, o número de vagens, a altura das plantas, o peso da matéria seca da raiz, do caule e das folhas foram diminuindo à medida que aumentava a densidade do solo, embora nas densidades intermediárias $(1,20$ e 1,35) se tenha notado uma tendência de aumento naquelas variáveis. A produção de soja não foi afetada pela compactação do solo, com exceção do número de vagens da cultivar IAC-14, que apresentou diferenças em razão do tratamento. Os resultados sugerem que as duas cultivares podem ser bem adaptadas a solos compactados, nos níveis analisados.
\end{abstract}

Termos para indexação: Glycine max, anatomia vegetal, sistema radicular, compactação do solo, densidade do solo.

\section{ROOT STRUCTURAL ASPECTS AND DEVELOPMENT OF SOYBEAN IN COMPACTED SOILS}

ABSTRACT - The present study aimed at evaluating the effect of soil compaction on the root anatomy and plant development of two soybean (Glycine max (L.) Merrill) cultivars, IAC-8 and IAC-14, in pots. A clayey soil collected, from a superficial $(0-200 \mathrm{~mm})$ layer was used. The compaction levels consisted of 0.95 (control), $1.20,1.35$ and $1.50 \mathrm{~kg} \mathrm{~L}^{-1}$, which were obtained by compaction of some soil mass with a hydraulic press inside of iron cylinders. The soil compaction did not affect the anatomic structure of the roots, in any of the two cultivars. In the IAC-8, the leaf number, plant height and the dry matter of roots and stem decreased with the increase of soil density, and the root length was increased. In the IAC-14, the leaf number, foliar area, pod number, plant height, and weight of the dry matter of roots, stem and leaves decreased as the soil density increased, except for the intermediate densities (1.20 and 1.35), in which a trend to increase was observed in these variables. The soybean production was not affected by soil compaction, except for pod number in IAC-14, which showed differences as a function of the treatment. The results suggest that both cultivars can be well adapted to compacted soils in the analysed levels of compaction.

Index terms: Glycine max, plant anatomy, root systems, soil compaction, soil density.

\section{INTRODUÇÃO}

O elevado nível de mecanização na agricultura tem ocasionado a compactação do solo. Sabe-se que

${ }^{1}$ Aceito para publicação em 24 de junho de 1999.

${ }^{2}$ Bióloga, M.Sc., Instituto Agronômico (IAC), Centro de Recursos Genéticos Vegetais e Jardim Botânico, Caixa Postal 28, CEP 13001-970 Campinas, SP. E-mail: rachelqv@barao.iac.br

${ }^{3}$ Eng. Agrôn., Dr., IAC-Centro de Plantas Graníferas. um solo pode ser quimicamente bom, mas se a compactação ocorre as plantas não se beneficiam adequadamente dos nutrientes, uma vez que o desenvolvimento de novas raízes fica prejudicado, e é nelas que ocorre a maior taxa de absorção. Além disso, com a compactação, diminuem os espaços livres do solo, e, conseqüentemente, a quantidade de oxigênio disponível na rizosfera, podendo ser limitante para o desempenho dos processos metabólicos da planta. 
O sistema radicular da soja, em condições normais de cultivo, distribui-se quase totalmente nos primeiros $150 \mathrm{~mm}$ do solo. Essa massa de raízes corresponde a $40 \%$, no mínimo, da superfície radicular (Raper \& Barber, 1970; Mitchell \& Russel, 1971). Em soja cultivada em solo não-irrigado, $67 \%$ das raízes localizam-se nos primeiros $300 \mathrm{~mm} ; 16 \%$ entre $300 \mathrm{~mm}$ e $900 \mathrm{~mm}$, e $17 \%$ abaixo de $900 \mathrm{~mm}$, em comparação com $71 \%, 21 \%$ e $9 \%$ nas respectivas camadas em soja irrigada (Mayaki et al., 1976). O aprofundamento do sistema radicular é extremamente importante em culturas normalmente não-irrigadas, como acontece com a soja em nossas condições. Segundo Stone et al. (1976), pequenas porções do sistema radicular nas camadas mais profundas do solo seriam suficientes para o suprimento hídrico da soja.

Diversos trabalhos têm abordado o sistema radicular, a nutrição e a produção da soja em relação à compactação do solo, como os de Nogueira \& Manfredini (1983), Johnson et al. (1990) e Rosolem et al. (1994), mas poucos são os que analisam a estrutura anatômica, como o de Baligar et al. (1975), realizado em um solo arenoso-barrento ("Marietta sandy loam").

A cultivar de soja IAC-8 é uma das mais plantadas atualmente, e a cultivar IAC-14 apresenta ótimo desempenho em plantio direto, graças à capacidade exploratória das suas raízes.

O objetivo deste trabalho foi estudar aspectos anatômicos das raízes das cultivares de soja IAC- $8 \mathrm{e}$ IAC-14, bem como o seu crescimento, em função da densidade de solos compactados.

\section{MATERIAL E MÉTODOS}

O experimento foi conduzido em vasos de cerâmica com $230 \mathrm{~mm}$ de diâmetro e $600 \mathrm{~mm}$ de altura, com solo Latossolo Roxo da camada superficial (0-200 mm) amostrado no Núcleo Experimental de Campinas (IAC). O delineamento experimental foi inteiramente casualizado, em esquema fatorial $4 \times 2$, com quatro níveis de compactação e duas cultivares de soja, com três repetições. Os níveis de compactação constituíram-se de: 0,95 (solo original = controle), 1,20, 1,35 e 1,50 $\mathrm{kg} \mathrm{L}^{-1}$, obtidos através de massa conhecida de solo, compactada com prensa hidráulica em cilindro de ferro, de $150 \mathrm{~mm}$ de altura, e de diâmetro correspondente ao vaso. Os cilindros de ferro foram coloca- dos $100 \mathrm{~mm}$ abaixo da superfície do vaso, e o espaço existente entre o cilindro e a parede do vaso foi preenchido por espuma. A camada superior ao cilindro e a inferior continham solo com densidade original $\left(0,95 \mathrm{~kg} \mathrm{~L}^{-1}\right)$.

Sementes de cultivares de soja (Glycine max (L.) Merrill) IAC-8 e IAC-14 foram submetidas à inoculação de Bradyrhizobium japonicum e semeadas nos vasos, utilizando-se dez sementes por vaso. Após a emergência das plântulas, foi feito um desbaste, sendo deixadas três por vaso. Os vasos foram irrigados periodicamente, de forma a manter o nível de água sempre próximo à capacidade de campo, e mantidos ao ar livre, sendo recolhidos em casa de vegetação à noite e em períodos de chuva.

Aos 91 dias após o plantio, as plantas já continham vagens com grãos totalmente formados, embora verdes, e, segundo Kaspar et al. (1978), nesse estádio de desenvolvimento não ocorre mais crescimento radicular. Nessa fase, as raízes foram retiradas, e amostras de três plantas por tratamento foram obtidas para estudos anatômicos. Foram amostradas a região onde estava o cilindro de compactação, denominada região superior (solo compactado), e a região inferior (solo original) ao cilindro. Foram mensuradas, também, as seguintes variáveis: comprimento da raiz; peso da matéria seca da raiz, do caule, da folha e da vagem; número de folhas e de vagens; área foliar e altura da planta. A área foliar foi estimada a partir do peso da matéria seca de folhas de área conhecida, empregando-se regra de três.

Para a confecção de lâminas permanentes, as raízes foram cortadas em fragmentos de $0,5 \mathrm{~cm}^{2}$, os quais foram fixados em F.A.A. 50\% (Johansen, 1940), desidratados em série alcoólico-etílica, incluídos em parafina e cortados em micrótomo rotativo, com $12 \mu \mathrm{m}$ de espessura. Os cortes foram corados com Safranina-"alcian blue" (Gabrielli, 1992).

Para verificar o efeito da compactação no desenvolvimento das raízes, optou-se por obter as medidas de raízes em estrutura secundária, uma vez que esse crescimento ocorre logo no início do desenvolvimento das raízes de soja e porque as raízes, em estrutura primária, são muito finas, o que dificulta a obtenção dos cortes. Embora as raízes estivessem em estrutura secundária, apresentavam diversas fases de desenvolvimento, uma vez que as amostras foram obtidas em posições diferentes em relação ao ápice, tanto na amostra da região superior do vaso, onde estava o cilindro, quanto na da região inferior. Nesse caso, medidas do diâmetro das raízes não seriam comparáveis. Estimou-se, então, a razão entre o raio externo e interno ao câmbio vascular, através de 20 medidas por planta, em cada tratamento, obtidas do raio externo ao câmbio vascular - compreendido pelos floemas secundário e primário e 
periderme - e do raio interno ao câmbio vascular - compreendido pelos xilemas secundário e primário. Tais medidas foram obtidas em microscópio, utilizando-se ocular micrométrica.

Os dados foram submetidos à análise de variância, comparando-se os modelos através de regressão polinomial a $5 \%$.

\section{RESULTADOS E DISCUSSÃO}

A estrutura anatômica da raiz primária da soja é do tipo protostelo tetrarco, com as células do córtex maiores do que as do estelo e arranjadas com espaços intercelulares, enquanto as do estelo são compactas. As raízes laterais geralmente são menores do que a principal, podendo ser diarcas, triarcas ou tetrarcas. A epiderme, a endoderme e o periciclo apresentam-se com uma única camada de células, corroborando a descrição de Bell (1934). Entretanto, Sun (1955) descreveu, em seu trabalho, um periciclo com duas a três camadas adjacentes ao protoxilema e uma a duas adjacentes ao floema, e atribuiu as diferenças entre os seus resultados e os dos outros autores, às diferenças existentes entre cultivares.

$\mathrm{O}$ crescimento secundário ocorre de modo semelhante ao descrito por Esau (1977) no que se refere às dicotiledôneas herbáceas. Os tecidos vasculares e a periderme formam-se a partir do câmbio e do felogênio, respectivamente. $O$ câmbio vascular entra em atividade e dá início ao crescimento secundário, originando o xilema e o floema secundários. $\mathrm{O}$ parênquima radial dos tecidos vasculares secundários normalmente são contínuos entre o floema e o xilema secundários. Com o aumento em espessura da raiz, a epiderme e uma parte externa do córtex se destacam, sendo produzida, por sua vez, a periderme (Figs. 1 e 2). $\mathrm{O}$ xilema secundário contém elementos de vaso de vários diâmetros (Figs. 1 e 2), e, na maioria dos casos, paredes secundárias com espessamento reticulado ou pontuado (Fig. 3 , setas), não sendo observadas diferenças em função dos níveis de compactação do solo e das cultivares. Nas raízes primárias de feijoeiro, foi observado um aumento no número de vasos de metaxilema (xilema primário) com o aumento da densidade do solo, sendo que o diâmetro destes vasos permanecia constante (Jaramillo et al., 1992).

Pode-se observar, nas Figs. 1 e 2, que o aumento na densidade do solo, máximo de $1,50 \mathrm{~kg} \mathrm{~L}^{-1}$, não evidenciou maior espessamento das paredes celulares dos elementos de vaso do xilema, ao contrário dos resultados obtidos por Baligar et al. (1975), embora esses autores tenham trabalhado com solos de tipos diferentes e com compactações mais altas, variando de 1,65 a 1,95 $\mathrm{kg} \mathrm{L}^{-1}$. É importante ressaltar que, embora a raiz da foto 5 da Fig. 1 - a qual se desenvolveu à densidade de $1,35 \mathrm{~kg} \mathrm{~L}^{-1}$ - apresente uma diferenciação no desenvolvimento secundário, isto é, a atividade cambial não foi uniforme em todo o seu diâmetro, a diferença não foi causada pela densidade do solo, uma vez que essa característica ocorreu também em densidades mais baixas. Como pode ser observado nas demais densidades, o desenvolvimento não é totalmente uniforme nas raízes das plantas de soja.

As diferenças quanto à razão entre o raio externo e o raio interno ao câmbio vascular entre as cultivares IAC-8 e IAC-14 foram significativas, tanto na região superior quanto na região inferior, o que indica diferenças entre as cultivares (Tabela 1). A cultivar IAC-8 possui a razão entre os raios externo e interno maior do que a IAC-14. Porém, fazendo-se comparações, dentro de cada cultivar, entre as regiões superior e inferior das raízes, observaram-se diferenças não significativas na razão entre o raio externo e o raio interno ao câmbio vascular, ou seja, o aumento da densidade do solo não alterou a espessura da raiz em nenhuma dessas regiões.

Os efeitos das compactações também foram analisados separadamente em cada região da raiz e cultivar. Em nenhuma dessas comparações houve diferenças significativas, com exceção da região inferior das raízes da cultivar IAC-8, que apresentou efeito linear significativo, ou seja, com o aumento da densidade do solo houve um decréscimo na razão entre os raios externo e interno (Tabela 1). Rosolem et al. (1994) também verificaram que não houve efeito significativo do aumento da densidade do solo no diâmetro das raízes.

Sun (1955) observou diferenças no desenvolvimento de raízes primárias de soja, em diferentes condições de aeração. Segundo esse autor, em soluções nutritivas aeradas as raízes apresentavam comprimento maior, diâmetro menor, raízes laterais numerosas e pêlos absorventes esparsos, ao passo que em condições não aeradas, possuíam comprimento menor, diâmetro maior e abundância de pêlos absorventes. 

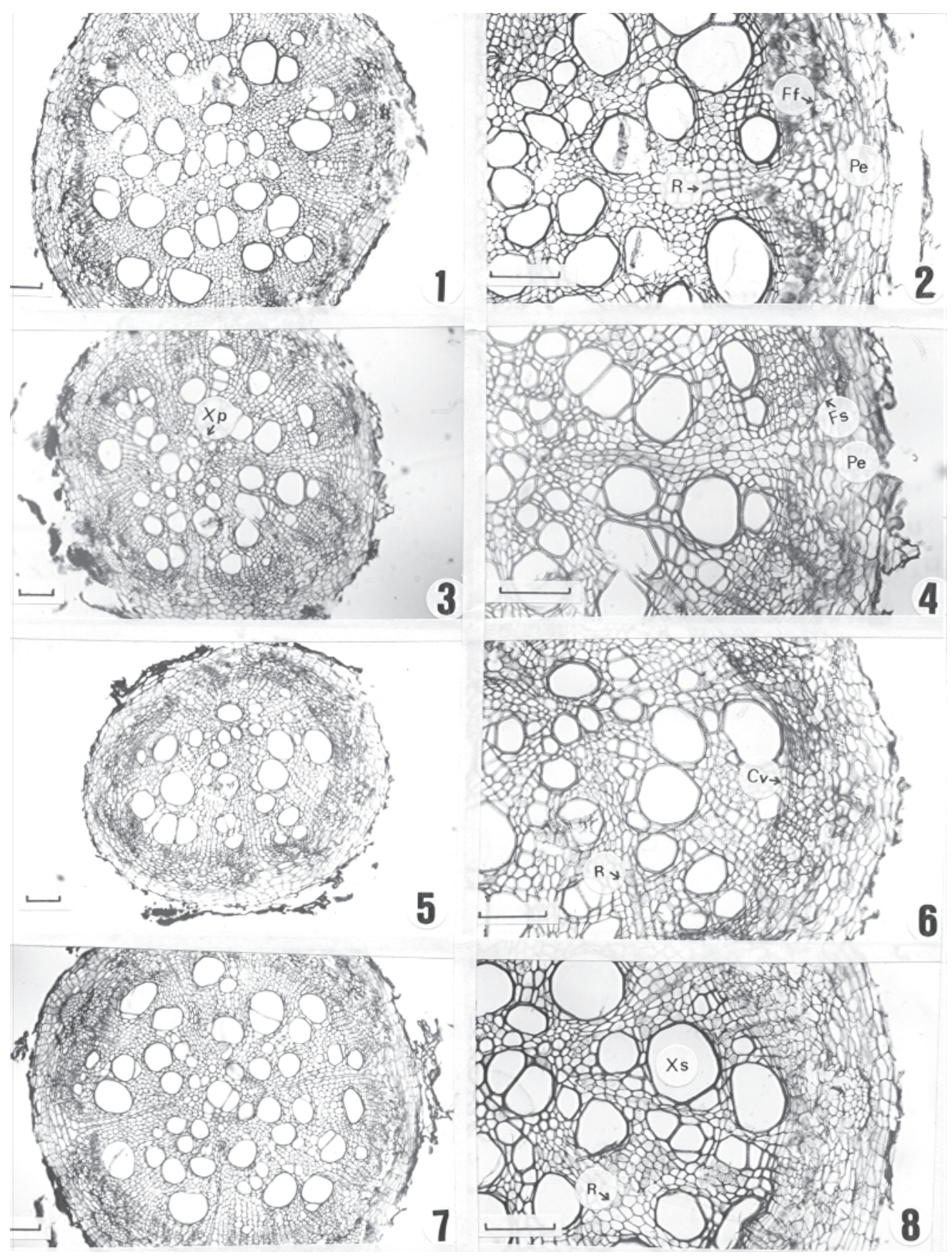

FIG. 1. Cortes transversais de raízes de Glycine max (L.) Merrill cv. IAC-8 desenvolvidas em diferentes condições de compactação de solo: 1 e $2-0,95 \mathrm{~kg} \mathrm{~L}^{-1} ; 3$ e 4- $1,20 \mathrm{~kg} \mathrm{~L}^{-1} ; 5$ e 6- 1,35 kg L $\mathrm{k}^{-1}$ e 7 e 8- 1,50 $\mathrm{kg} \mathrm{L}^{-1}$. Cv: câmbio vascular; Ff: fibras do floema; Fs: floema secundário; Pe: periderme; R: raio; Xp: xilema primário; Xs: xilema secundário; barra da escala $=100 \mu \mathrm{m}$. 

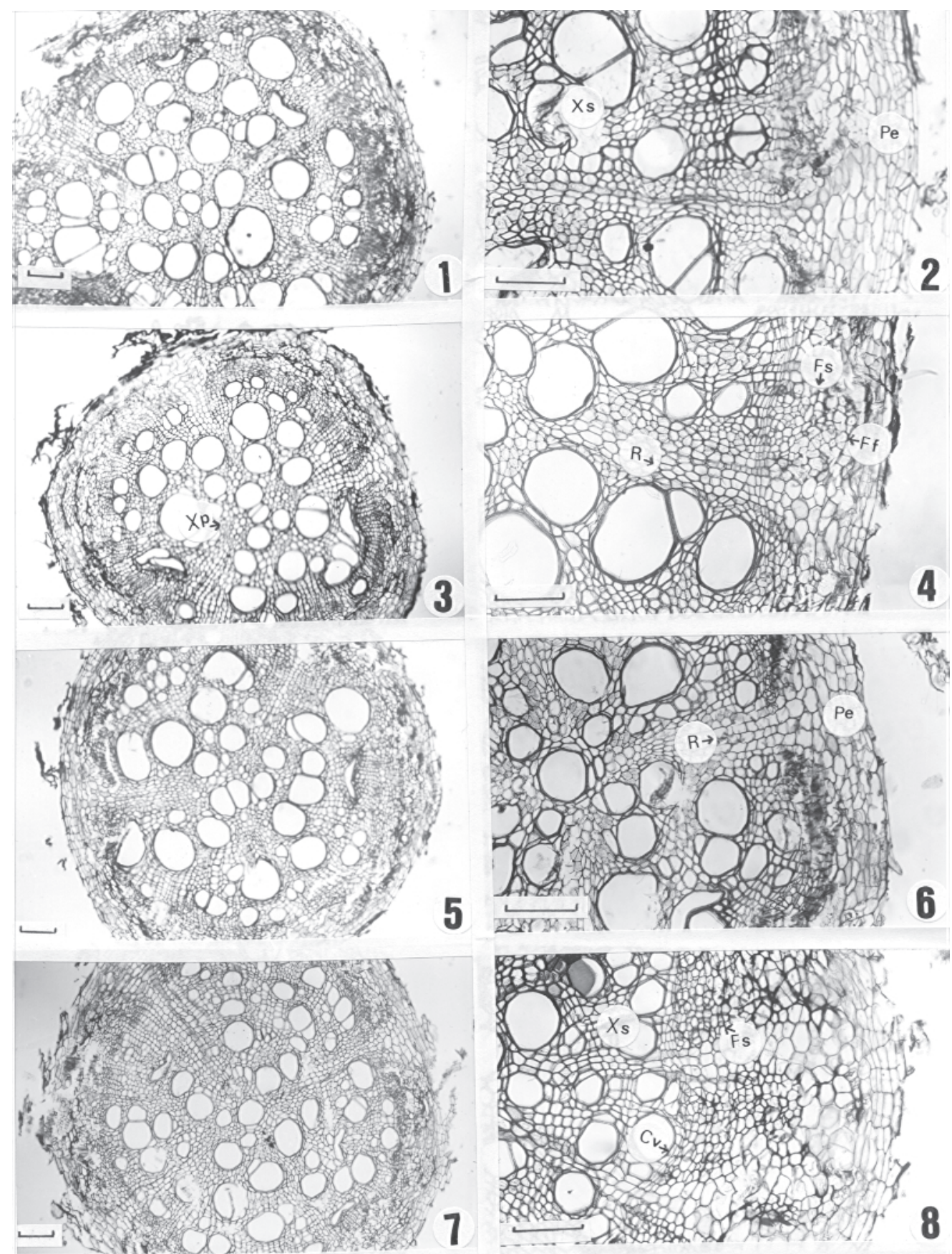

FIG. 2. Cortes transversais de raízes de Glycine max (L.) Merrill cv. IAC-14 desenvolvidas em diferentes condições de compactação de solo: 1 e $2-0,95 \mathrm{~kg} \mathrm{~L}^{-1} ; 3$ e 4- 1,20 kg L $\mathrm{kg}^{-1} ; 5$ e 6- 1,35 kg L $\mathrm{k}^{-1}$ e 7 e 8- 1,50 $\mathrm{kg} \mathrm{L}^{-1}$. Cv: câmbio vascular; Ff: fibras do floema; Fs: floema secundário; Pe: periderme; R: raio; Xp: xilema primário; Xs: xilema secundário; barra da escala $=100 \mu \mathrm{m}$. 

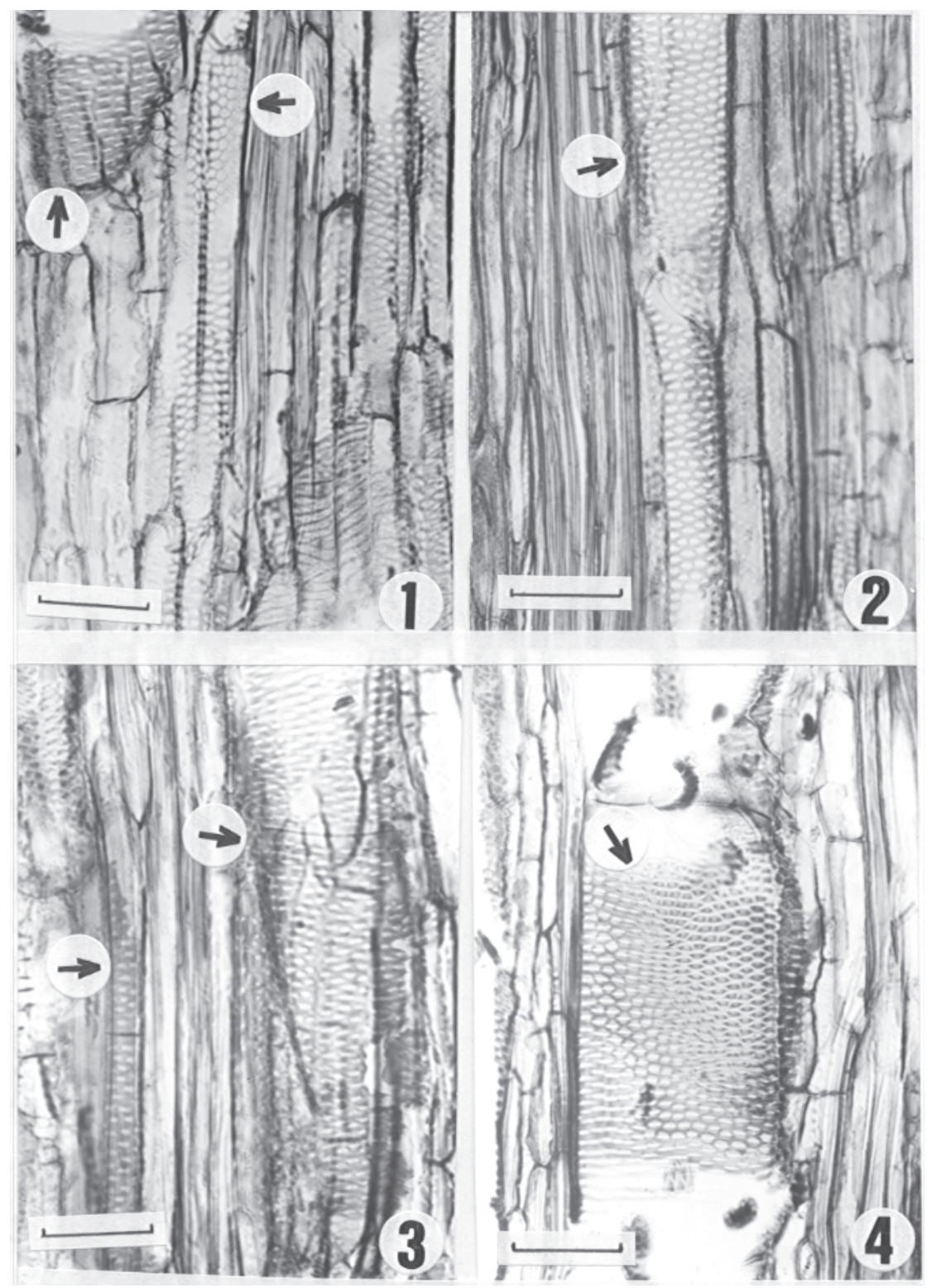

FIG. 3. Cortes longitudinais tangenciais de raízes de Glycine max (L.) Merrill cv. IAC-14 desenvolvidas em diferentes condições de compactação do solo: 1- 0,95 $\mathrm{kg} \mathrm{L}^{-1} ; 2-1,20 \mathrm{~kg} \mathrm{~L}^{-1} ; 3-1,35 \mathrm{~kg} \mathrm{~L}^{-1}$ e 4- 1,50 $\mathrm{kg} \mathrm{L}^{-1}$. As setas indicam os elementos de vaso pontuados. Barra da escala $=50 \mu \mathrm{m}$.

É provável que, no nível de compactação mais alto deste trabalho $\left(1,50 \mathrm{~kg} \mathrm{~L}^{-1}\right)$, a disponibilidade de oxigênio tenha sido suficiente para o desenvolvimento dessas raízes, ou, então, as cultivares IAC-8 e
IAC-14 tenham-se adaptado melhor do que a cultivar Monroe estudada por Sun (1955).

Os resultados do desenvolvimento das plantas nas diferentes condições de compactação do solo 
estão apresentados nas Tabelas 2 e 3 . Verificaram-se diferenças entre as cultivares em relação ao comprimento da raiz, número de folhas, altura da planta, peso da matéria seca do caule e da folha, sendo a média dessas variáveis maior na cultivar IAC-8, exceto quanto ao número de folhas.

Na cultivar IAC-8, o número de folhas, a altura da planta e o peso da matéria seca da raiz e do caule diminuíram com o aumento da densidade do solo, ao passo que o comprimento da raiz aumentou. Tais resultados podem ser observados por meio das equações dessas regressões, nas quais o coeficiente de regressão (b) do comprimento da raiz é positivo, ao passo que nas demais variáveis o coeficiente é negativo. É possível que as plantas tenham procurado alcançar áreas não-compactadas do vaso (região inferior do cilindro) mediante maior desenvolvimento do comprimento das raízes, sem, no entanto, promover aumento no peso da matéria seca das raízes. $\mathrm{O}$ desenvolvimento da parte aérea, entretanto, mostrouse afetado com o aumento da densidade do solo, como pode ser observado pela diminuição da altura da planta, pelo peso da matéria seca do caule e da folha, e mediante o número de folhas e da área foliar. O menor número de folhas observado com o aumento da densidade do solo parece ter sido compensado por uma expansão do limbo foliar, resultando em diferenças apenas no efeito quadrático na área foliar e no peso da matéria seca da folha, em função do aumento da densidade do solo. A área foliar e o peso da matéria seca da folha, embora também tenham diminuído com o aumento da densidade do solo, apresentaram médias mais altas à densidade de $1,20 \mathrm{~kg} \mathrm{~L}^{-1}$.

$\mathrm{Na}$ cultivar IAC-14, o número de folhas, a área foliar, o número de vagens, a altura da planta, o peso da matéria seca da raiz, do caule e da folha ficaram menores com o aumento da densidade do solo, porém nas densidades intermediárias $\left(1,20\right.$ e 1,35 $\left.\mathrm{kg} \mathrm{L}^{-1}\right)$ observou-se tendência de aumento nessas variáveis. Isto pode ser observado mediante o efeito quadrático significativo nas Tabelas 2 e 3. Rosemberg (1964) também observou, em diversas culturas anuais, que uma moderada compactação do solo foi benéfica às plantas, quando comparada a um solo solto e desagregado, e admitiu haver uma relação parabólica entre produção de plantas e densidade do solo.

TABELA 1. Médias, significância do teste $F(p<0,05)$ e equações de regressão da razão entre o raio externo e o raio interno ao câmbio vascular das cultivares IAC-8 e IAC-14 de Glycine max (L.) Merrill nas regiões superior e inferior da raiz, nas quatro densidades de compactação do solo, sendo 0,95 a densidade original (controle).

\begin{tabular}{|c|c|c|c|c|}
\hline \multirow[t]{2}{*}{ Região } & \multirow{2}{*}{$\begin{array}{c}\text { Densidade } \\
\text { do solo }\left(\mathrm{kg} \mathrm{L}^{-1}\right)\end{array}$} & \multicolumn{2}{|c|}{ Cultivares } & \multirow[t]{2}{*}{$\mathrm{F}^{1}$} \\
\hline & & IAC-8 & IAC-14 & \\
\hline \multirow[t]{4}{*}{ Superior } & 0,95 & 0,57 & 0,44 & \\
\hline & 1,20 & 0,57 & 0,45 & \\
\hline & 1,35 & 0,57 & 0,47 & \\
\hline & 1,50 & 0,49 & 0,45 & \\
\hline Média & & 0,55 & 0,45 & $\mathrm{~L} ; \mathrm{y}=0,65-0,10 \mathrm{x}$ \\
\hline $\mathrm{F}^{2}$ & & $\mathrm{~ns}$ & ns & \\
\hline \multirow[t]{4}{*}{ Inferior } & 0,95 & 0,68 & 0,54 & \\
\hline & 1,20 & 0,60 & 0,44 & \\
\hline & 1,35 & 0,51 & 0,43 & \\
\hline & 1,50 & 0,58 & 0,46 & \\
\hline Média & & 0,59 & 0,47 & $L ; y=0,72-0,12 x$ \\
\hline $\mathrm{F}^{2}$ & & $L ; y=0,69-0,039 x$ & ns & \\
\hline $\mathrm{F}^{3}$ & & $\mathrm{~ns}$ & ns & \\
\hline
\end{tabular}


TABELA 2. Médias, significância do teste $F(p<0,05)$ e equações de regressão do comprimento da raiz, do número de folhas, da área foliar, do número de vagens e da altura da planta das cultivares IAC-8 e IAC-14 de Glycine max (L.) Merrill em diferentes densidades de compactação do solo, sendo 0,95 a densidade original (controle).

\begin{tabular}{|c|c|c|c|}
\hline \multirow{2}{*}{$\begin{array}{c}\text { Densidade } \\
\text { do solo }\left(\mathrm{kg} \mathrm{L}^{-1}\right)\end{array}$} & \multicolumn{2}{|c|}{ Cultivares } & \multirow[t]{2}{*}{$\mathrm{F}^{1}$} \\
\hline & IAC-8 & IAC-14 & \\
\hline \multicolumn{4}{|c|}{ Comprimento da raiz (m) } \\
\hline 0,95 & 0,49 & 0,56 & \\
\hline 1,20 & 0,68 & 0,50 & \\
\hline 1,35 & 0,53 & 0,60 & \\
\hline 1,50 & 1,01 & 0,54 & \\
\hline Média & 0,68 & 0,55 & $L ; y=0,80-0,13 x$ \\
\hline $\mathrm{F}^{2}$ & $\begin{array}{c}L ; y=0,32+0,14 x \\
Q ; y=0,68-0,22 x+0,07 x^{2}\end{array}$ & ns & \\
\hline \multicolumn{4}{|c|}{ Número de folhas } \\
\hline 0,95 & 151,67 & 166,00 & \\
\hline 1,20 & 195,33 & 241,00 & \\
\hline 1,35 & 147,67 & 260,00 & \\
\hline 1,50 & 89,00 & 157,67 & \\
\hline Média & 145,92 & 206,17 & $L ; y=85,67+60,25 x$ \\
\hline $\mathrm{F}^{2}$ & $\begin{array}{c}L ; y=204,83-23,57 x \\
Q ; y=76,92+104,35 x-25,58 x^{2}\end{array}$ & $Q ; y=-14,00+221,07 x-44,33 x^{2}$ & \\
\hline \multicolumn{4}{|c|}{ Área foliar $\left(\mathrm{m}^{2}\right)$} \\
\hline 0,95 & 0,28 & 0,26 & \\
\hline 1,20 & 0,45 & 0,41 & \\
\hline 1,35 & 0,35 & 0,42 & \\
\hline 1,50 & 0,36 & 0,26 & \\
\hline Média & 0,36 & 0,34 & $\mathrm{~ns}$ \\
\hline $\mathrm{F}^{2}$ & $Q ; y=0,13+0,21 x-0,04 x^{2}$ & $Q ; y=-0,06+0,39 x-0,08 x^{2}$ & \\
\hline \multicolumn{4}{|c|}{ Número de vagens } \\
\hline 0,95 & 68,33 & 81,00 & \\
\hline 1,20 & 78,00 & 99,33 & \\
\hline 1,35 & 81,00 & 86,33 & \\
\hline 1,50 & 66,00 & 62,33 & \\
\hline Média & 73,33 & 82,25 & ns \\
\hline $\mathrm{F}^{2}$ & $\mathrm{~ns}$ & $\begin{array}{c}\mathrm{L} ; \mathrm{y}=99,50-6,90 \mathrm{x} \\
\mathrm{Q} ; \mathrm{y}=46,58+46,02 \mathrm{x}-10,58 \mathrm{x}^{2}\end{array}$ & \\
\hline \multicolumn{4}{|c|}{ Altura da planta (m) } \\
\hline 0,95 & 1,44 & 0,80 & \\
\hline 1,20 & 1,40 & 0,98 & \\
\hline 1,35 & 1,38 & 0,86 & \\
\hline 1,50 & 1,15 & 0,74 & \\
\hline Média & 1,34 & 0,84 & $\mathrm{~L} ; \mathrm{y}=1,84-0,50 \mathrm{x}$ \\
\hline $\mathrm{F}^{2}$ & $\begin{array}{c}L ; y=1,56-0,09 x \\
Q ; y=1,32+0,15 x-0,05 x^{2}\end{array}$ & $Q ; y=0,54+0,34 x-0,07 x^{2}$ & \\
\hline
\end{tabular}

${ }^{1}$ Entre as cultivares.

${ }^{2}$ Entre as compactações.

L: efeito linear significativo; Q: efeito quadrático significativo; ns: não-significativo. 
TABELA3. Médias, significância do teste $F(p<0,05)$ e equações de regressão da produção de matéria seca das cultivares IAC-8 e IAC-14 de Glycine max (L.) Merrill em diferentes densidades de compactação do solo, sendo 0,95 a densidade original do solo (controle).

\begin{tabular}{|c|c|c|c|}
\hline \multirow{2}{*}{$\begin{array}{c}\text { Densidade } \\
\text { do solo }\left(\mathrm{kg} \mathrm{L}^{-1}\right)\end{array}$} & \multicolumn{2}{|c|}{ Cultivares } & \multirow[t]{2}{*}{$\mathrm{F}^{1}$} \\
\hline & IAC-8 & IAC-14 & \\
\hline \multicolumn{4}{|c|}{ Peso da matéria seca da raiz (g mat. seca/vaso) } \\
\hline 0,95 & 6,12 & 5,97 & \\
\hline 1,20 & 9,22 & 8,65 & \\
\hline 1,35 & 5,40 & 6,42 & \\
\hline 1,50 & 5,47 & 4,59 & ns \\
\hline Média & 6,55 & 6,40 & \\
\hline $\mathrm{F}^{2}$ & $\begin{array}{c}L ; y=7,99-0,58 x \\
Q ; y=4,22+3,20 x-0,75 x^{2}\end{array}$ & $\begin{array}{c}\mathrm{L} ; \mathrm{y}=7,99-0,63 \mathrm{x} \\
Q ; \mathrm{y}=2,36+5,00 \mathrm{x}-1,13 \mathrm{x}^{2}\end{array}$ & \\
\hline \multicolumn{4}{|c|}{ Peso da matéria seca do caule (g mat. seca/vaso) } \\
\hline 0,95 & 19,83 & 12,20 & \\
\hline 1,20 & 23,83 & 18,17 & \\
\hline 1,35 & 20,37 & 17,30 & \\
\hline 1,50 & 12,60 & 12,67 & \\
\hline Média & 19,16 & 15,08 & $L ; y=23,23-4,08 x$ \\
\hline $\mathrm{F}^{2}$ & $\begin{array}{c}\mathrm{L} ; \mathrm{y}=25,45-2,52 \mathrm{x} \\
\mathrm{Q} ; \mathrm{y}=10,74+12,19 \mathrm{x}-2,94 \mathrm{x}^{2}\end{array}$ & $Q ; y=1,70+13,30 x-2,65 x^{2}$ & \\
\hline \multicolumn{4}{|c|}{ Peso da matéria seca da folha (g mat.seca/vaso) } \\
\hline 0,95 & 12,93 & 11,70 & \\
\hline 1,20 & 18,83 & 15,77 & \\
\hline 1,35 & 15,30 & 15,63 & \\
\hline 1,50 & 14,87 & 8,73 & \\
\hline Média & 15,48 & 12,96 & $\mathrm{~L} ; \mathrm{y}=18,01-2,52 \mathrm{x}$ \\
\hline $\mathrm{F}^{2}$ & $Q ; y=7,00+8,14 x-1,58 x^{2}$ & $Q ; y=1,51+12,80 x-2,74 x^{2}$ & \\
\hline \multicolumn{4}{|c|}{ Peso da matéria seca da vagem (g mat. seca/vaso) } \\
\hline 0,95 & 5,57 & 5,68 & \\
\hline 1,20 & 3,92 & 5,64 & \\
\hline 1,35 & 6,69 & 7,59 & \\
\hline 1,50 & 4,42 & 4,34 & \\
\hline Média & 5,15 & 5,82 & ns \\
\hline $\mathrm{F}^{2}$ & $\mathrm{~ns}$ & $\mathrm{~ns}$ & \\
\hline
\end{tabular}

1 Entre as cultivares

2 Entre as compactações.

L: efeito linear significativo; Q: efeito quadrático significativo; ns: não-significativo.

Do mesmo modo, Jaramillo et al. (1992) observaram, em feijoeiro desenvolvido em solos compactados, alterações na morfologia externa e também uma redução na altura total da planta e no desenvolvimento das raízes e ramos. Na raiz principal ocorreu redução em seu alongamento e maior formação de raízes laterais.

Em experimento realizado por Nogueira \& Manfredini (1983), com a cultivar de soja Santa Rosa, observou-se que a compactação não afetou a absorção de macronutrientes, mas diminuiu o peso da matéria seca das raízes e do caule; houve maior desenvolvimento das raízes nas regiões superior e inferior ao cilindro, como forma de controlar os problemas causados pela compactação. Resultados semelhantes foram obtidos por Rosolem et al. (1994) com a cultivar Primavera. Sabe-se que em condições de campo a camada compactada não se apresenta como 
uma massa contínua, de densidade global constante, ao longo de grandes extensões (Barbieri et al., 1984, 1985), e, portanto, as raízes procuram espaços livres no solo para se desenvolver.

Embora existam diferenças significativas entre as densidades do solo, em algumas das variáveis estudadas, a produtividade das plantas de soja não foi afetada; o efeito da compactação não foi significativo em relação ao número e peso da matéria seca das vagens, na cultivar IAC-8, e ao peso da matéria seca das vagens, na cultivar IAC-14. Tais resultados corroboram os obtidos por Johnson et al. (1990), em que o decréscimo no crescimento vegetativo não resultou em decréscimo proporcional na produtividade de grãos.

\section{CONCLUSÕES}

1. Não ocorrem alterações anatômicas nas raízes, em estruturas secundárias, nas cultivares de soja IAC-8 e IAC-14, nos níveis de compactação estudados.

2. Densidades de compactação do solo de até $1,50 \mathrm{~kg} \mathrm{~L}^{-1}$ não afetam o número e o peso da matéria seca das vagens da cultivar de soja IAC-8, nem o peso da matéria seca das vagens da cultivar IAC-14.

\section{REFERÊNCIAS}

BALIGAR, V.C.; NASH, V.E.; HARE, M.L.; PRICE JUNIOR, J.A. Soybean root anatomy as influenced by soil bulk density. Agronomy Journal, Madison, v.67, p.842-844, 1975.

BARBIERI, J.L.; POLI, D.M.; DONZELLE, J.L. Compactação e descompactação de solo em áreas de reforma de canaviais. Boletim Técnico Coopersucar, São Paulo, v.25, p.14-20, 1984.

BARBIERI, J.L.; POLI, D.M.; DONZELLE, J.L. Os Latossolos roxos e a cultura da cana-de-açúcar. Boletim Técnico Coopersucar, São Paulo, v.32, p.110,1985 .

BELL, W.H. Ontogeny of the primary axis of soya max. Botanical Gazette, Chicago, v.95, p.622-635, 1934.

ESAU, K. Anatomy of seed plants. 2.ed. New York : John Wiley, 1977. 550p.

GABRIELLI, A.C. Contribuição ao estudo anatômico da raiz de Pyrostegia venusta (Ker) Miers-Bignoniaceae.
Revista Brasileira de Botânica, São Paulo, v.15, n.2, p.95-104, 1992.

JARAMILlO, G.; WHITE, J.W.; CRUZ, G. de la. The effect of soil compaction on differentiation of late metaxylem in common bean (Phaseolus vulgaris L.). Annals of Botany, London, v.70, p.105-110, 1992.

JOHANSEN, D.A. Plant microtechnique. New York : McGraw Hill, 1940. 523p.

JOHNSON, J.F.; VOORHEES, W.B.; NELSON, W.W.; RANDALL, G.W. Soybean growth and yield as affected by surface and subsoil compaction. Agronomy Journal, Madison, v.82, p.973-979, 1990.

KASPAR, T.C.; STANLEY, C.D.; TAYLOR, H.M. Soybean root growth during the reproductive stages of development. Agronomy Journal, Madison, v.70, p.1105-1197, 1978 .

MAYAKI, W.C.; STONE, L.R.; TEARE, I.D. Irrigated and non-irrigated soybean, corn and grains sorghum root systems. Agronomy Journal, Madison, v.68, p.532-534, 1976.

MITCHELL, R.L.; RUSSEL, W.J. Root development and rooting patterns of soybeans (Glycine max (L.) Merrill) evaluated under field conditions. Agronomy Journal, Madison, v.63, p.313-316, 1971.

NOGUEIRA, S. dos S.S.; MANFREDINI, S. Influência da compactação do solo no desenvolvimento da soja. Pesquisa Agropecuária Brasileira, Brasília, v.18, n.9, p.973-976, set. 1983.

RAPER, D.C.; BARBER, S.A. Rooting systems of soybean. I. Differences in root morphology among varieties. Agronomy Journal, Madison, v.62, p.581584, 1970.

ROSEMBERG, N.J. Response of plants to the physical effects of soil compaction. Advance in Agronomy, San Diego, v.16, p.181-196, 1964.

ROSOLEM, C.A.; ALMEIDA, A.C. da S.; SACRAMENTO, L.V.S. do. Sistema radicular e nutrição da soja em função da compactação do solo. Bragantia, Campinas, v.53, n.2, p.259-266, 1994.

STONE, L.R.; TEARE, I.D.; MICKELL, C.D.; MAYAKI, W.C. Soybean root development and soil water depletion. Agronomy Journal, Madison, v.68, p.677-680, 1976.

SUN, C.N. Growth and development of primary tissues in aerated and non-aerated roots of soybean. Bulletin of the Torrey Botanical Club, Lancaster, v.82, n.6, p.491-502, 1955. 